\title{
Paget's Disease of the Skull
}

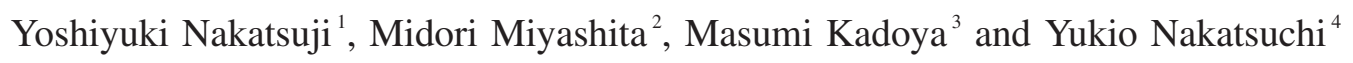

Key words: skull, cotton wool appearance, SPECT-CT, occipital condyle, Paget's disease of bone

(Intern Med Advance Publication)

(DOI: 10.2169/internalmedicine.7696-21)

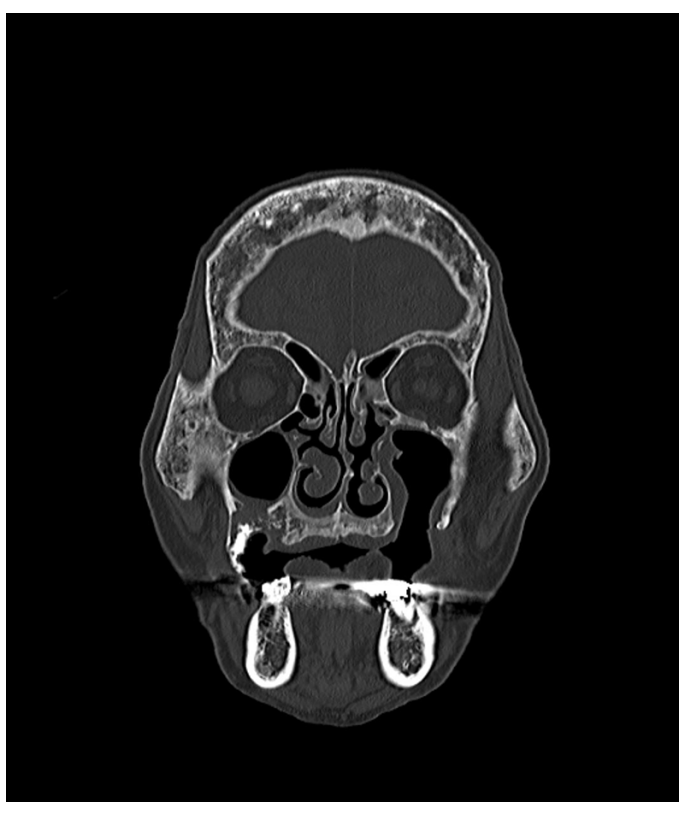

Picture 1.
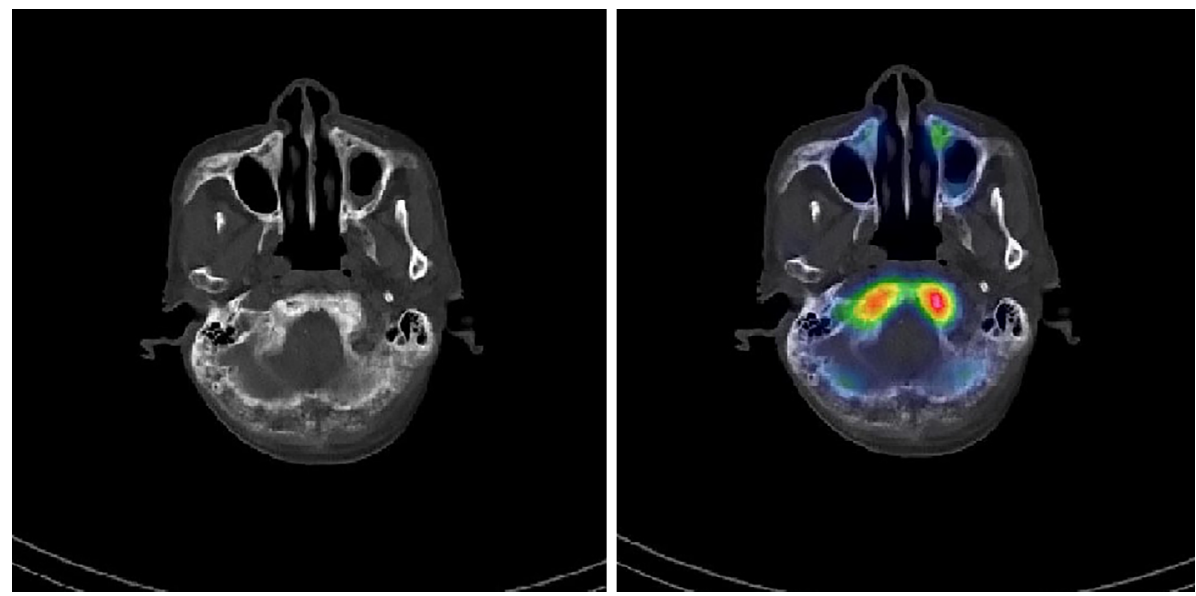

Picture 3.

${ }^{1}$ Department of Gastroenterology and Internal Medicine, Marunouchi Hospital, Japan, ${ }^{2}$ Department of Dental Surgery, Marunouchi Hospital, Japan, ${ }^{3}$ Department of Radiology, Marunouchi Hospital, Japan and ${ }^{4}$ Department of Orthopedics, Marunouchi Hospital, Japan Received: April 5, 2021; Accepted: August 11, 2021; Advance Publication by J-STAGE: October 5, 2021 Correspondence to Dr. Yoshiyuki Nakatsuji, nakatsuji_y@marunouchi.or.jp 


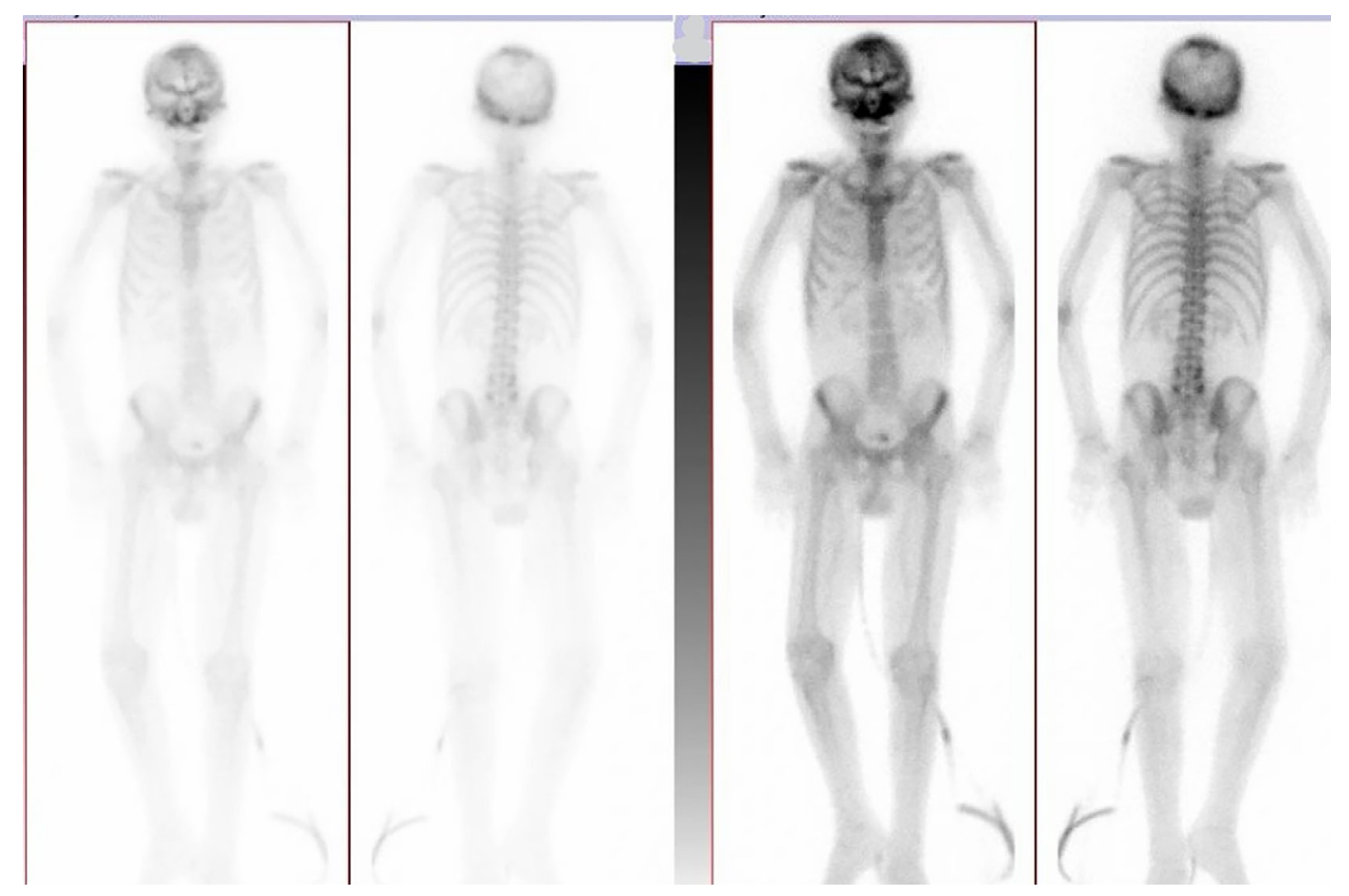

Picture 4.

A 96-year-old man was admitted to our hospital because of urosepsis with shock. A physical examination revealed a body temperature of $37.8{ }^{\circ} \mathrm{C}$, blood pressure of $74 / 41$ $\mathrm{mmHg}$, hearing loss of the left ear, maxillary teeth defects and right costovertebral angle tenderness. The corrected calcium level was $9.4 \mathrm{mg} / \mathrm{dL}$, and alkaline phosphatase was 380 IU/L (normal, 115-330). Bone formation markers were mildly elevated, and bone resorption markers were normal. Head computed tomography (CT) revealed a mixture of osteolytic and osteoblastic lesions (Picture 1). Skull X-ray showed no punched-out lesions but the characteristic 'cotton wool' appearance (Picture 2). Single-photon-emission CT (SPECT)-CT (Picture 3) of bone scintigraphy (Picture 4) showed that there was a strong radio isotope uptake in the occipital condyle. He was diagnosed with Paget's disease of bone, which is a very rare metabolic bone disease, showing an incidence of about 2.8 per million in Japan $(1,2)$. The administration of vitamin $\mathrm{D}$ and calcium preparations was started without bisphosphonate.

The authors state that they have no Conflict of Interest (COI).

\section{Acknowledgements}

We thank Mr. Hiroshi Hirano for his assistance in capturing the X-ray images and Ms. Taduko Yamagishi, Ms. Mie Kurata and Ms. Nao Furukawa for their assistance in preparing the manuscript.

\section{Patient consent: Obtained.}

\section{References}

1. Hashimoto J, Ohno I, Nakatsuka K, et al. Prevalence and clinical features of Paget's disease of bone in Japan. J Bone Miner Metab 24: 186-190, 2006

2. Ralston SH, Corral-Gudino L, Cooper C, et al. Diagnosis and management of Paget's disease of bone in adults: a clinical guideline. J Bone Miner Res 34: 579-604, 2019.

The Internal Medicine is an Open Access journal distributed under the Creative Commons Attribution-NonCommercial-NoDerivatives 4.0 International License. To view the details of this license, please visit (https://creativecommons.org/licenses/ by-nc-nd/4.0/).

\section{(C) The Japanese Society of Internal Medicine Intern Med Advance Publication}

